\title{
LA-UR-17-30555
}

Approved for public release; distribution is unlimited.

Title: Nuclear Forensics and Radiochemistry: Chemistry

Author(s): $\quad$ Rundberg, Robert S.

Intended for: $\quad$ Lecture series at UC Berkeley

Issued: $\quad$ 2017-11-17 
Disclaimer:

Los Alamos National Laboratory, an affirmative action/equal opportunity employer, is operated by the Los Alamos National Security, LLC for the National Nuclear Security Administration of the U.S. Department of Energy under contract DE-AC52-06NA25396. By approving this article, the publisher recognizes that the U.S. Government retains nonexclusive, royalty-free license to publish or reproduce the published form of this contribution, or to allow others to do so, for U.S. Government purposes. Los Alamos National Laboratory requests that the publisher identify this article as work performed under the auspices of the U.S. Department of Energy. Los Alamos National Laboratory strongly supports academic freedom and a researcher's right to publish; as an institution, however, the Laboratory does not endorse the viewpoint of a publication or guarantee its technical correctness. 


\title{
Nuclear Forensics and Radiochemistry: Chemistry \\ Robert S. Rundberg
}

\begin{abstract}
:
The chemical behavior of radioactive elements can differ from conventional wisdom because the number of atoms can be unusually small. Kinetic effects and unusual oxidation states are phenomena that make radiochemistry different from conventional analytic chemistry. The procedures developed at Los Alamos are designed to minimize these effects and provide reproducible results over a wide range of sample types. The analysis of nuclear debris has the additional complication of chemical fractionation and the incorporation of environmental contaminants. These are dealt with through the use of three component isotope ratios and the use of appropriate end members.
\end{abstract}




\section{Nuclear Forensics and \\ Radiochemistry: Chemistry}

\section{Lecture 6}




\section{Forensics of a nuclear blast}

If an atomic bomb were to detonate in a U.S. city. nuclear sleuths would use a wide range of tools to puzzle out the nature of the bomb and who was responsible. Each weapon type has a distinct fingerprint encompassing the waveforms it emits and the fallout it unleashes.

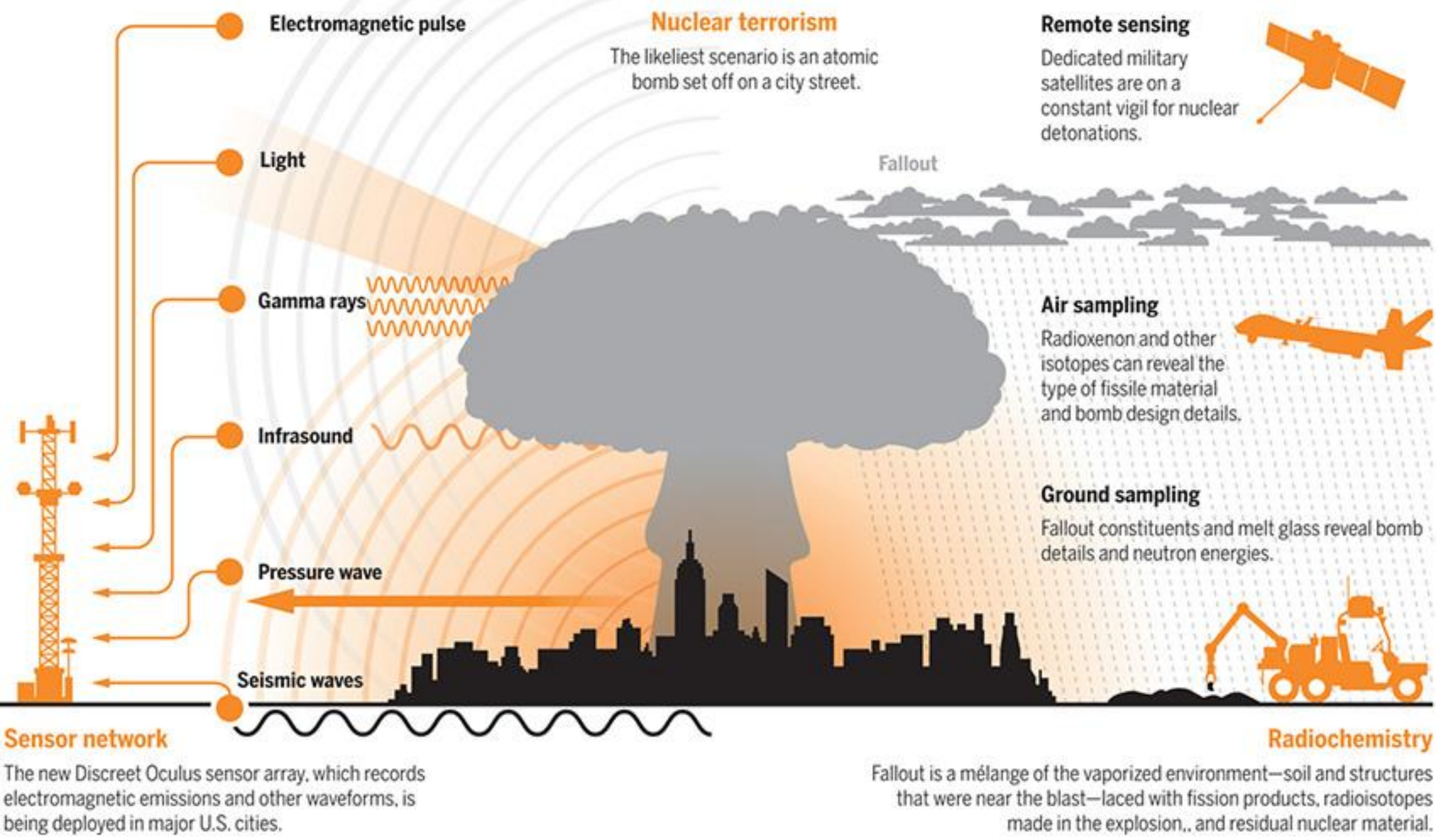




\section{Post Detonation Debris}

- The radiochemical evidence will be in at least two forms

- Glassy debris i.e., Trinitite

- Particulate on filter paper flown through the radioactive plume

- Multiple Samples are required to correct for fractionation or environmental contamination

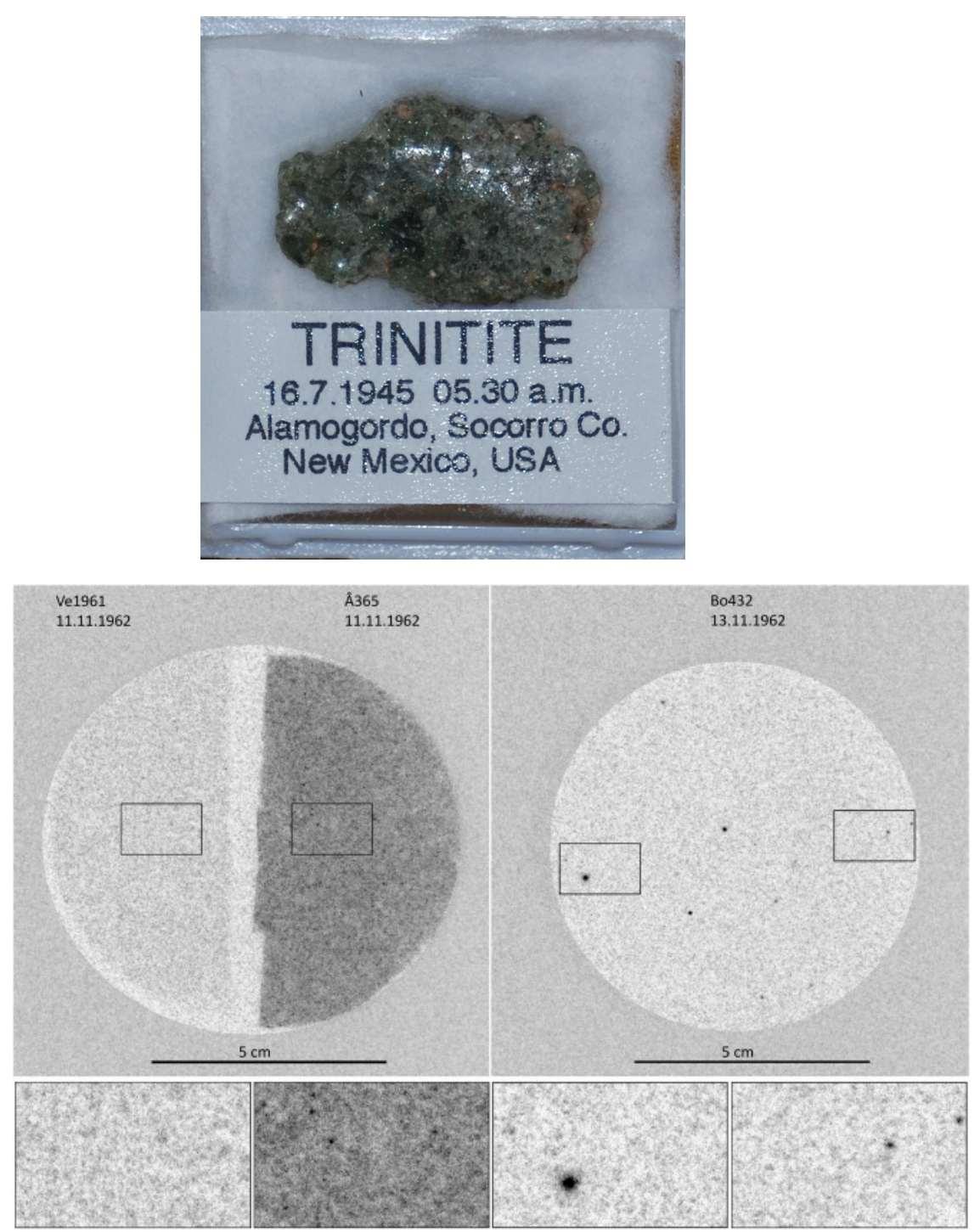




\section{Peculiarities of Radiochemistry}

- Carrier free radioactive elements can be a very small number of atoms.

- A desirable sample of 1e14 fissions per gram has only $6 \mathrm{e} 12$ atoms of ${ }^{99} \mathrm{Mo}$ a peak yield isotope

- A valley isotope ${ }^{111} \mathrm{Ag}$ would be about $2 \mathrm{e} 10$ atoms

- That is less than a micromole. Nano-mole for silver.

- Kinetics can be very slow at these concentrations.

- Depending on the nuclear process of formation the atoms can be in an unusual oxidation state. 


\section{Procedure for Dissolving Debris from}

LA-1721

- Step 1. Place the dried, pulverized sample in a cylindrical Teflon vessel of 100 -ml capacity. Add $25 \mathrm{ml}$ of fuming $\mathrm{HNO}_{3}, 100 \mathrm{ml}$ of cone $\mathrm{HClO}_{4}$, and, with care, $50 \mathrm{ml}$ of conc. $\mathrm{HF}$. Heat to strong fumes of $\mathrm{HClO}_{4}$ on a hot plate (medium setting). The solution process may be accelerated by placing an aluminum jacket around the Teflon container.

- Step 2. Cool, add another $50 \mathrm{ml}$ of conc. HF, and again evaporate to strong fumes of $\mathrm{HClO}_{4}$.

- Step 3. Repeat Step 2 twice. (If $10 \mathrm{~g}$ of debris are being dissolved, repeat Step 2 four times; add $\mathrm{HClO}_{4}$ as necessary to to prevent the sample from becoming dry.)

- Step 4. Evaporate until the volume is "'50 ml, cool, and add $100 \mathrm{ml}$ of $3 \mathrm{M} \mathrm{HCl}$. Warm slightly to dissolve any solids. 
- Step 5. Divide the solution among four 40-ml Vycor centrifuge tubes. Wash the Teflon vessel with $3 \mathrm{M} \mathrm{HCl}$ and add the washes to the centrifuge tubes. Centrifuge for $2 \mathrm{~min}$ at $3500 \mathrm{rpm}$. During the centrifugation wash the Teflon vessel under a stream of $\mathrm{H}_{2} \mathrm{O}$. Rub the inner surfaces well and flush them with $\mathrm{H}_{2} \mathrm{O}$ to remove adhering $\mathrm{SiO}_{2}$ particles, which may be discarded. The vessel is now ready for re-use in the following step.

- Step 6. Transfer the supernate to the clean Teflon vessel, add $50 \mathrm{ml}$ each of conc. $\mathrm{HF}$ and $\mathrm{HClO}_{4}$, and begin heating on a hot plate (medium setting).

- Step 7. Wash the precipitates in the centrifuge tubes with $3 \mathrm{M} \mathrm{HCl}$, centrifuge, and add the supernates to the Teflon vessel on the hot plate. 
- Step 8. To each of the precipitates remaining inthe centrifuge tubes add 2 to $3 \mathrm{ml}$ of $6 \mathrm{M} \mathrm{N}$ aOH and boil while stirring over a burner. Cool, acidify with $3 \mathrm{M} \mathrm{HCl}$, bring to a boil and centrifuge. Combine the supernates with those in the Teflon vessel. If more than a few grains of sand and/or any beta-gamma activity remain, repeat the $\mathrm{NaOH}-\mathrm{HCl}$ treatment until no sand is left or until it is no longer active. (For complete destruction of solids, repeat the sequence of Steps 2 through 8 until the sand is entirely dissolved.)

- Step 9. Heat the contents of the Teflon vessel to strong fumes of $\mathrm{HClO}_{4}$. Cool, add $50 \mathrm{ml}$ of conc. $\mathrm{HF}$, and evaporate the solution until the volume is $\sim 50 \mathrm{ml}$. Cool.

- Step 10. Add $100 \mathrm{ml}$ of $3 \mathrm{M} \mathrm{HCl}$ and warm slightly to dissolve any solid material. Divide the solution among four clean 40-ml Vycor centrifuge tubes and centrifuge at 3500 rpm. 
- Step 11. Filter the supernate through polypropylene "paper" into a labeled, graduated plastic bottle. Wash the Teflon vessel and the centrifuge tubes with $3 \mathrm{M} \mathrm{HCl}$, centrifuge, and filter the washes into the plastic bottle. If any precipitate remains in the centrifuge tubes, add 2 to 3 $\mathrm{ml}$ of $6 \mathrm{M} \mathrm{NaOH}$ and heat over a burner. Cool, neutralize with $3 \mathrm{M} \mathrm{HCl}$, centrifuge, and decant the supernate through the filter into the plastic bottle. Repeat the $\mathrm{NaOH}$ $\mathrm{HCl}$ treatment if a precipitate still remains in the centrifuge tubes.

- Step 12. Add $3 \mathrm{M} \mathrm{HCl}$ to make the concentration of the original sample in solution $\leq 7.5 \mathrm{mg} / \mathrm{ml}$. Heat the final solution overnight in a water bath at $\sim 90^{\circ} \mathrm{C}$. (For reasons that are not at all clear, this heat treatment gives a sample solution that may be analyzed satisfactorily. Without such treatment, results may be erratic.) 


\section{Notes on the Dissolution Procedure}

- The use of perchloric acid ensures that the radioactive elements are oxidized to their highest oxidation state.

- This is important for reproducibility.

- Some elements will be volatilized and, as a consequence, lost.

- Perchloric acid speeds the removal of silicates because is has a higher boiling point than most acids.

- The final step which involves heating overnight with 3 molar acid is clearly a step to ensure the slow kinetics of ligand formation in some elements is overcome. 


\section{Separation of the Elements}

- The procedures described in LA-1721 cover the separation of most of the elements on the periodic chart.

- Every procedure begins with adding 10 to 40 milligrams of carrier.

- The carrier ensures that chemical separation is reproducible and efficient

- The procedures, while similar to those in qualitative analysis, are designed to be very robust.

- These procedures have been used on samples from a variety of environmental settings

- Specific steps have been developed in some cases to remove problematic elements, e.g., iron. 


\section{Effects of a Nuclear Explosion}

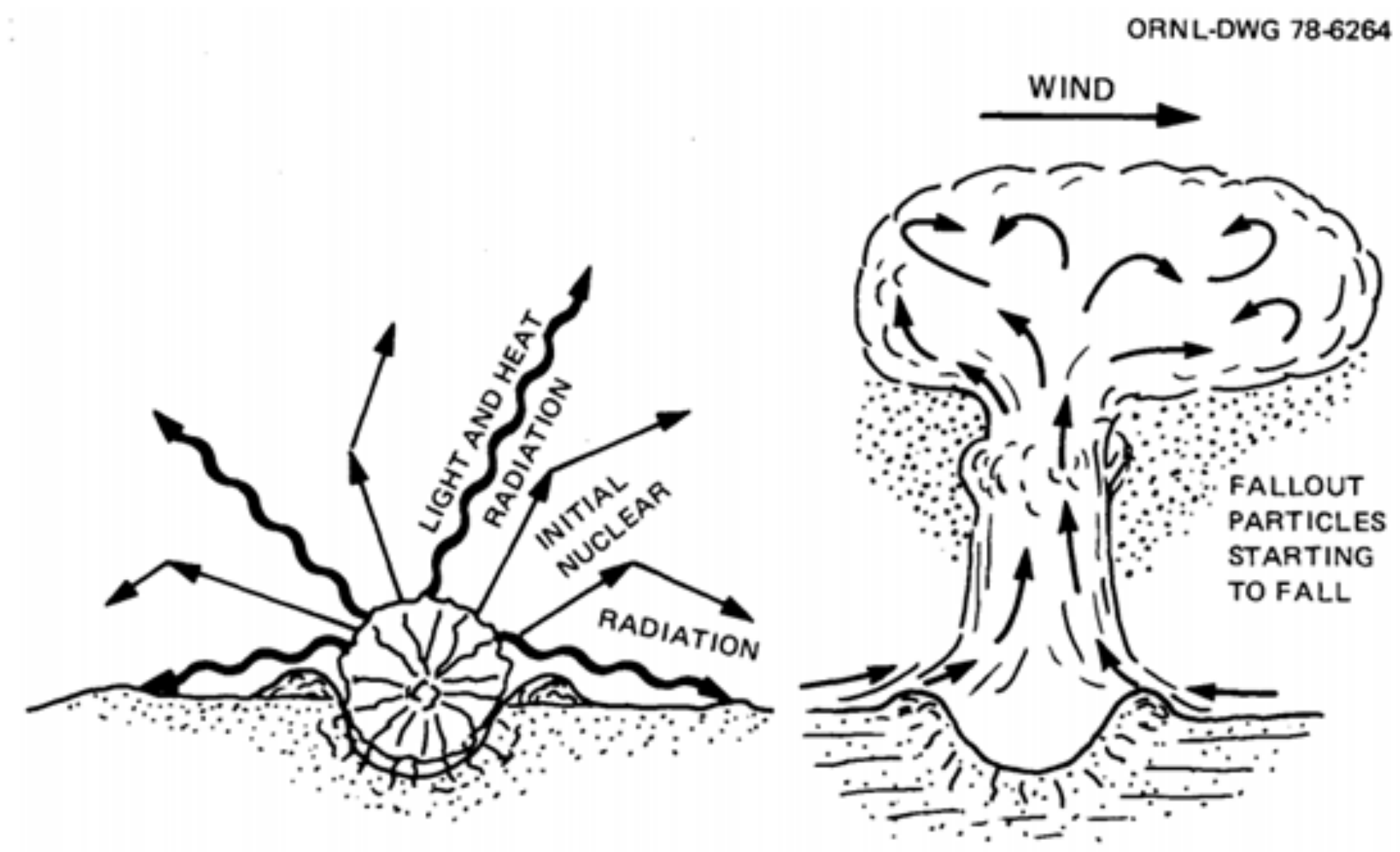




\section{Fractionation}

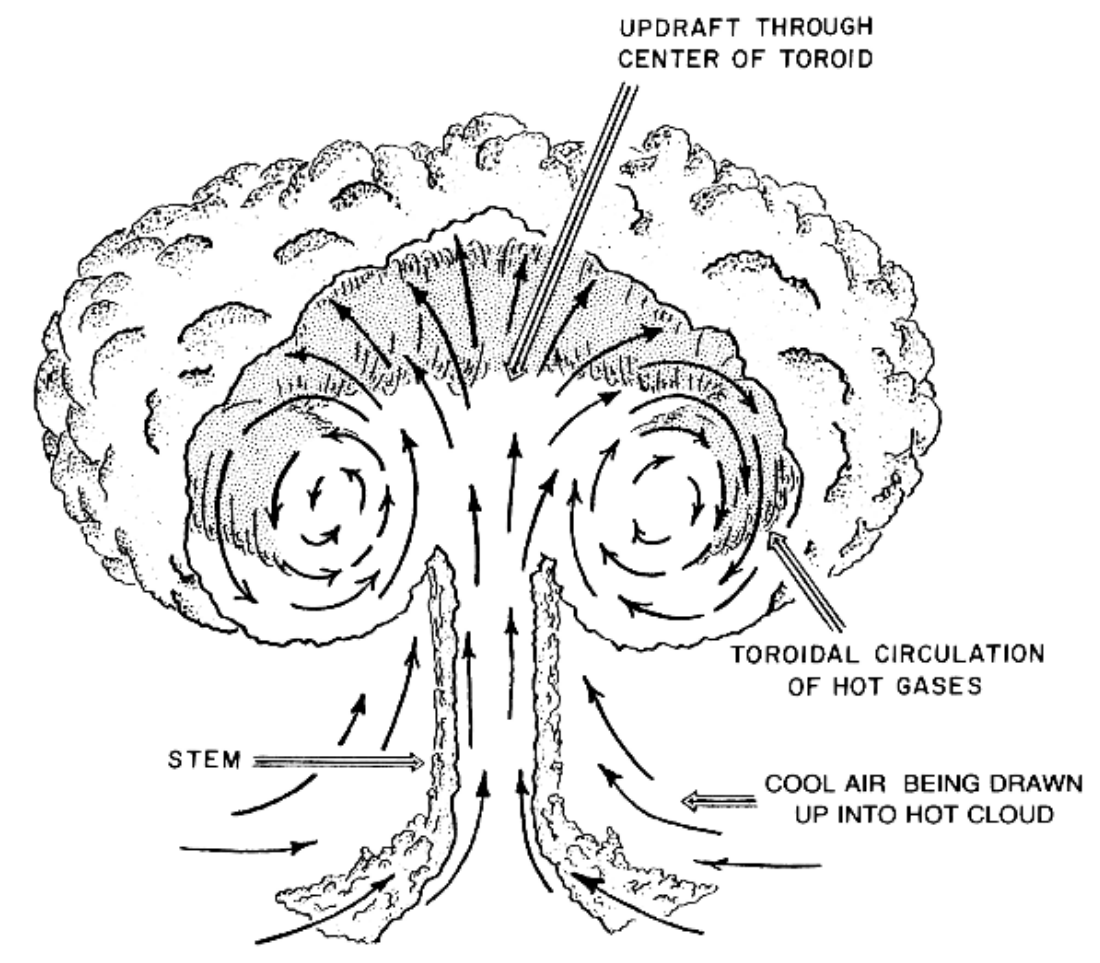

- Atmospheric tests from towers or balloons are not typically fractionated.

- Tests on or near the ground are highly fractionated because material from the soil environment is swept up into the cloud.

- Refractory elements are uniformly incorporated into the first condensing (refractory) material.

- Volatile elements are condensed on the surface of particles as they cool.

- Smaller particles have a higher surface area to mass ratio and therefore have a higher fraction of volatiles. 


\section{Fallout Pattern near a Nuclear Explosion}

The most hazardous fallout particles are readily visible as fine, sand-sized grains, but the lack of apparent fallout should not be misrepresented to mean radiation isn't present; therefore appropriate radiation monitoring should always be performed.. Fallout that is immediately hazardous to the public and emergency responders will descend to the ground within about 24 hours.

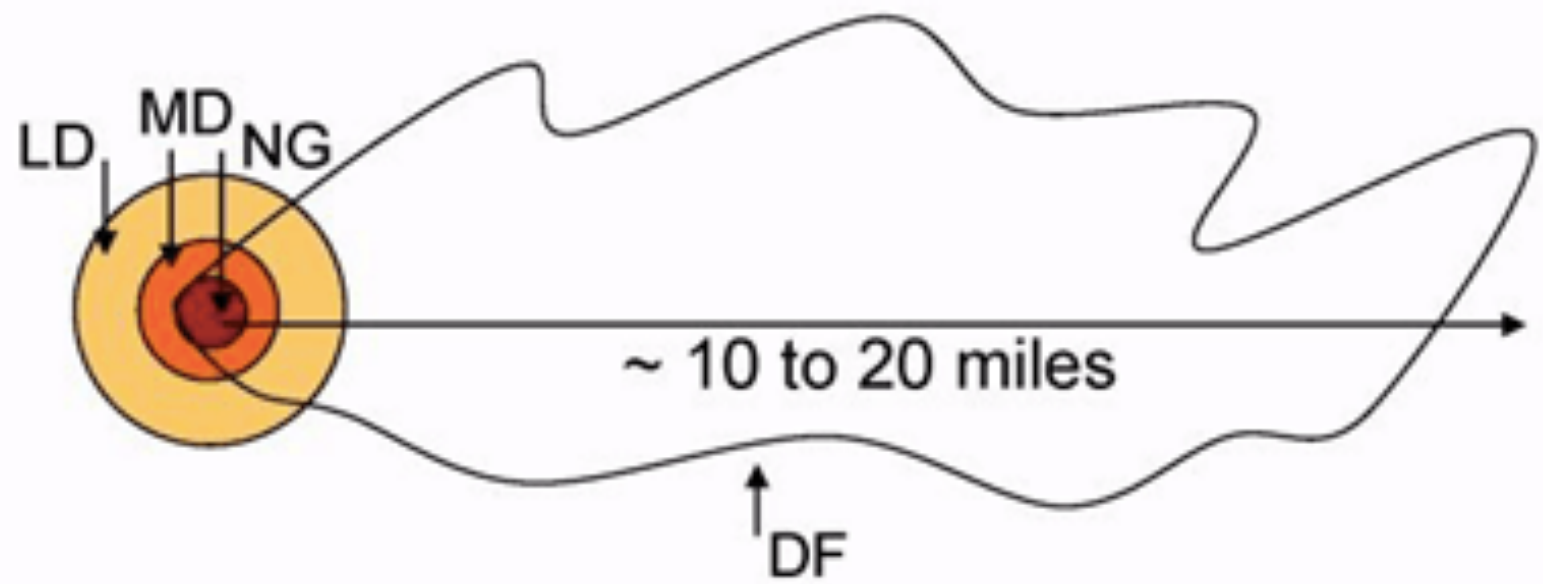

Figure 1.4: Representative dangerous fallout (DF) zone in which an early and direct threat from fallout radioactivity exists. A radiation exposure rate of $10 \mathrm{R} /$ hour is used to delimit this zone. 


\section{Fallout Debris in the Near Field}

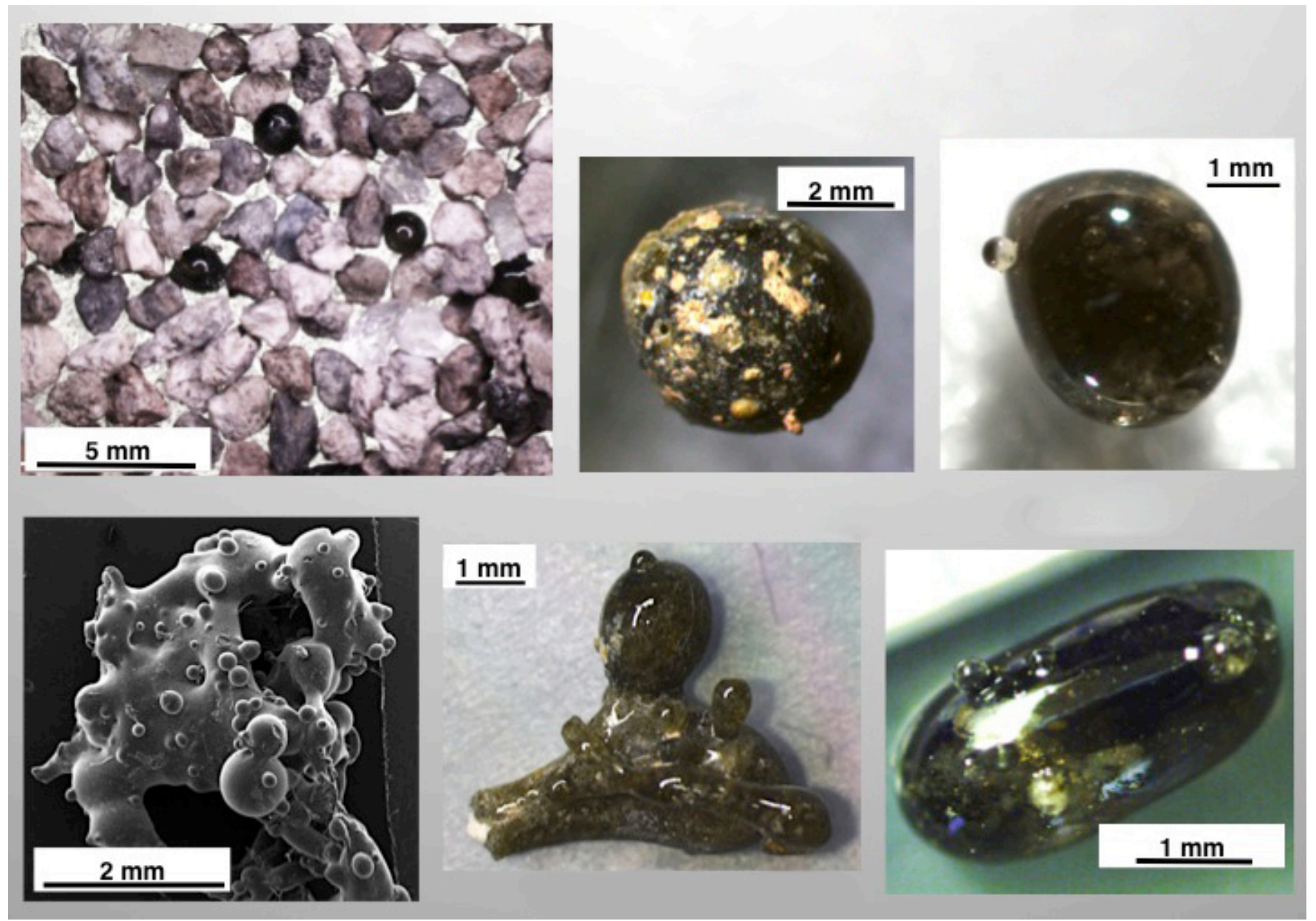




\section{Ce-141 is Volatile?}

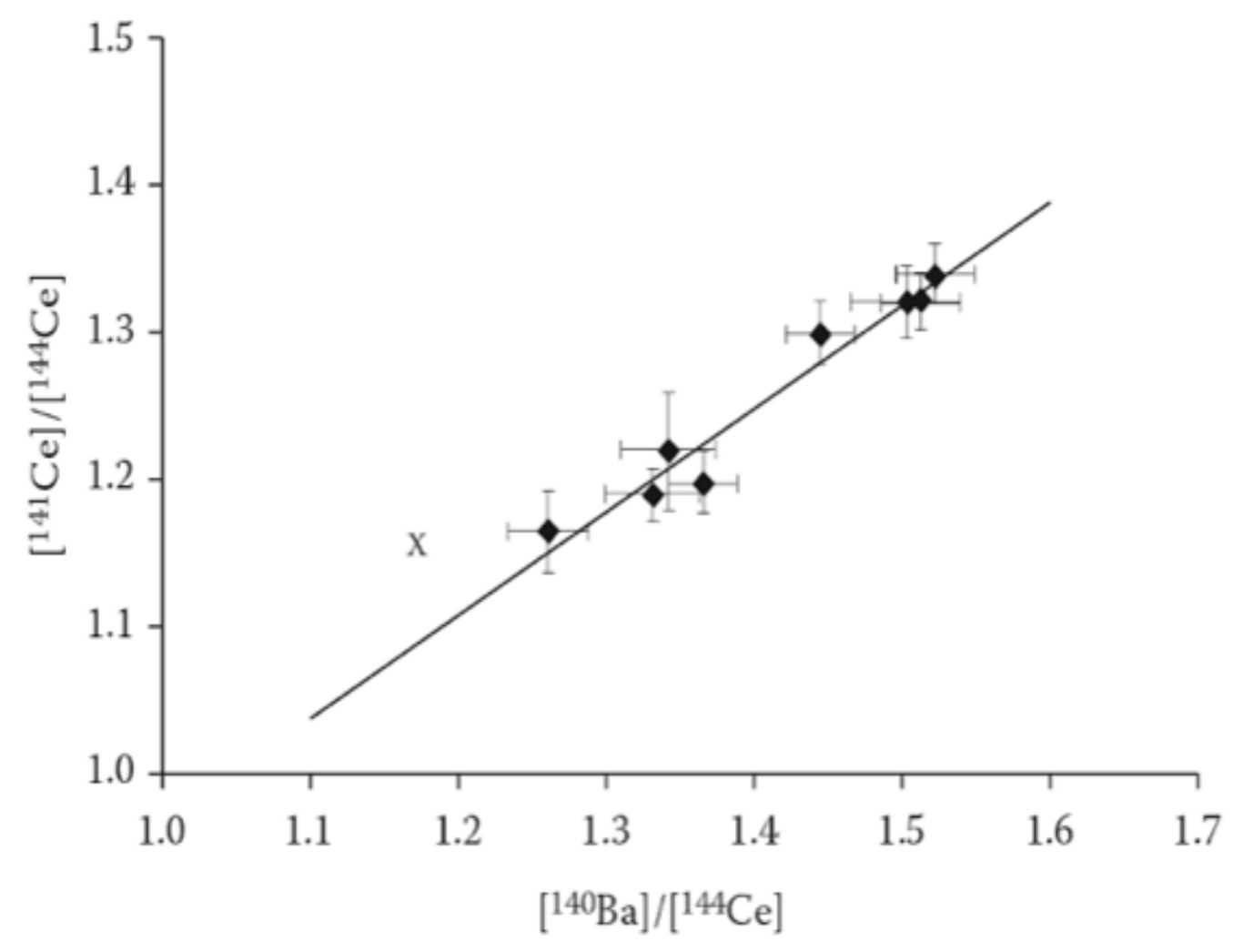

FIGURE 5.10 A three-isotope plot used in a mixing analysis of eight samples of fractionated debris collected downrange from a 1962 nuclear test. Diamonds are the experimental data, the diagonal line is a linear fit, and " $x$ " is the result of a calculation of homogeneous debris based on device performance. 
Fission Product Volatility Depends on its Precursors

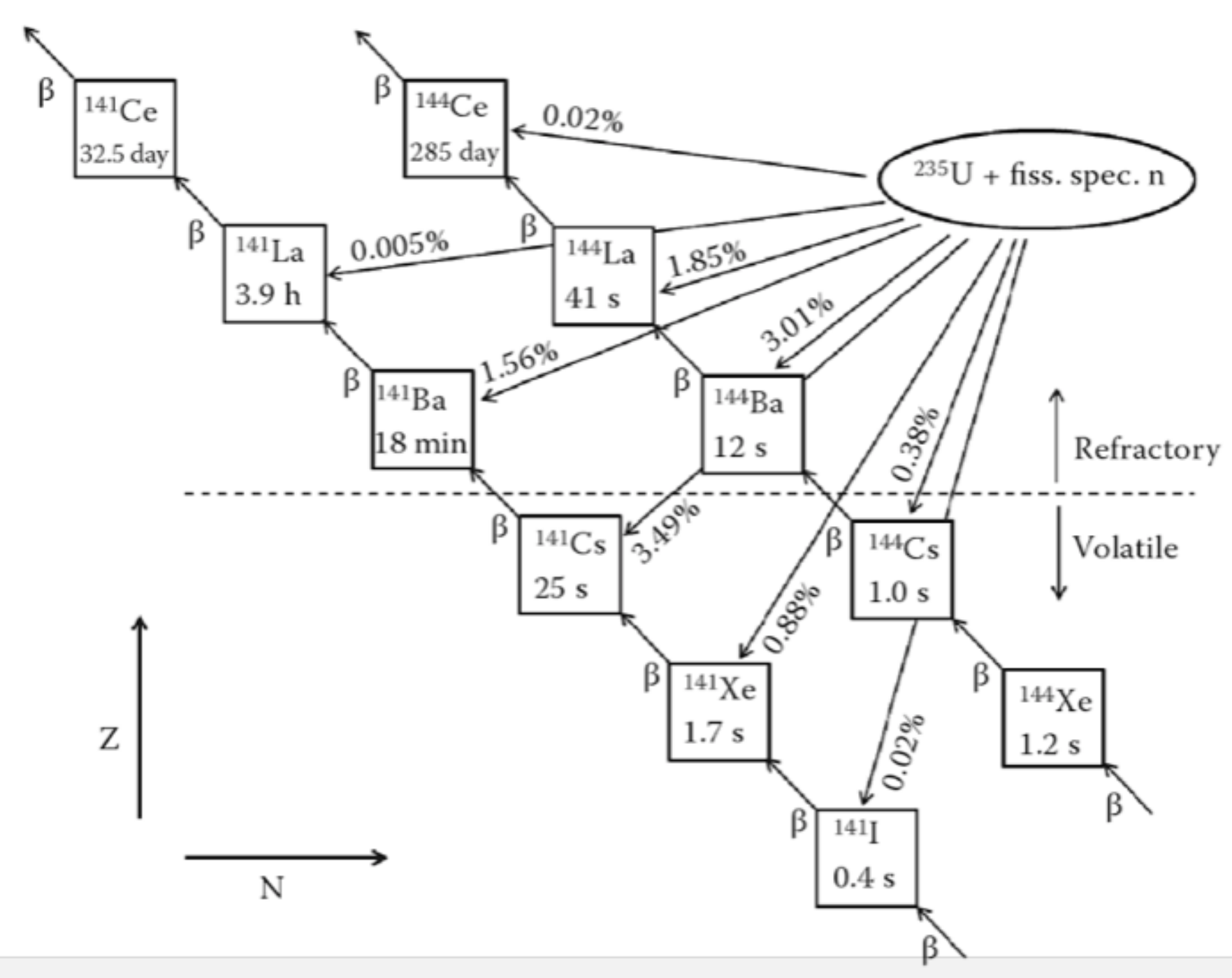




\section{Freiling Ratios}

- Science 133, 1992(1961)

- The reference ratio of ${ }^{95} \mathrm{Zr}$ to ${ }^{89} \mathrm{Sr}$ is a measure of fractionation. The larger the ratio the more the loss of volatile species.

- The logarithmic slope nears 1.0 (linear) for refractory species.

- Logarithmic slope less than 1 indicate volatility.

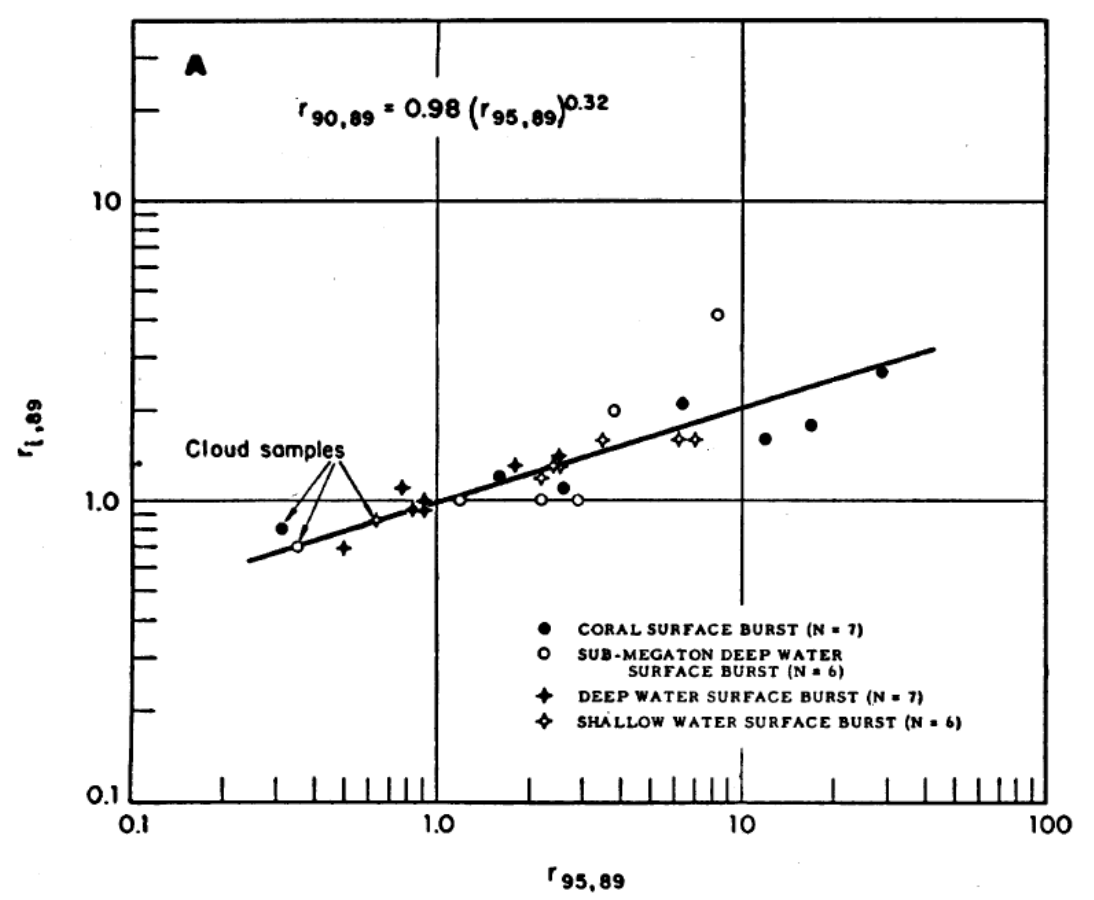




\section{Cesium-137 is as Volatile as Strontium-89}

${ }^{99} \mathrm{Mo}$

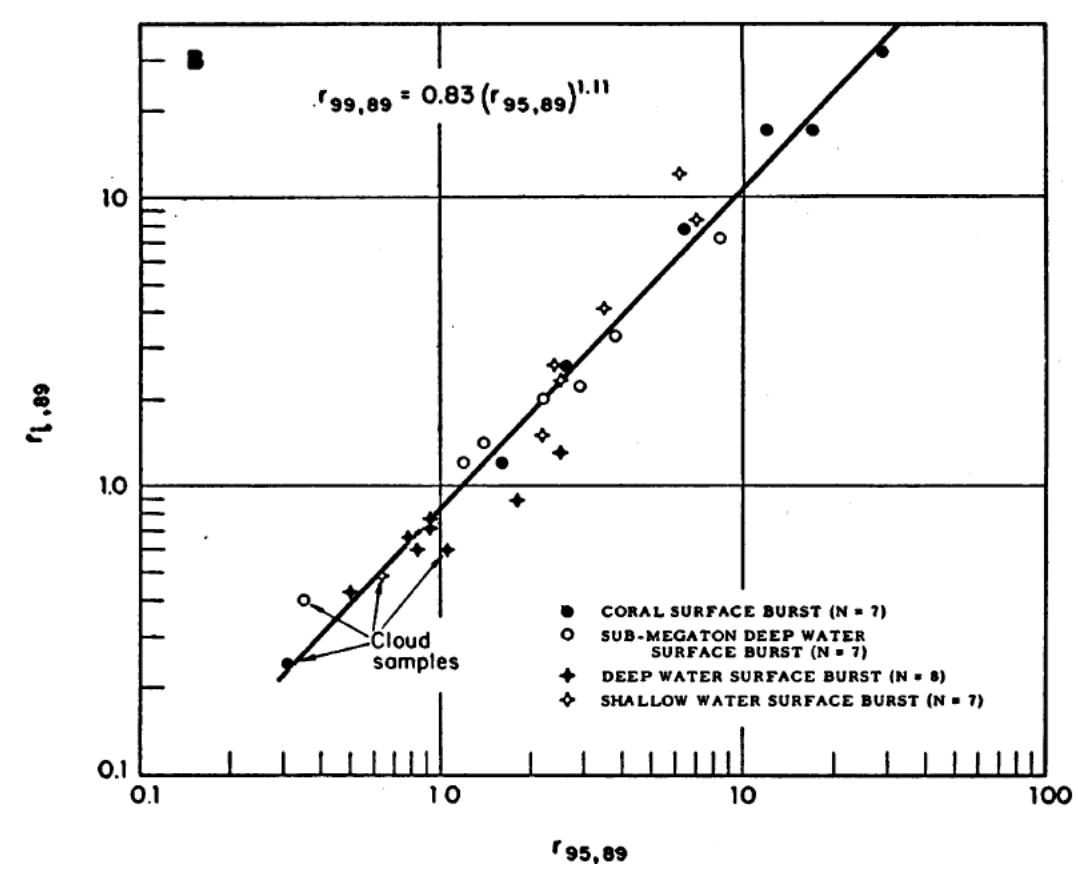

${ }^{137} \mathrm{Cs}$

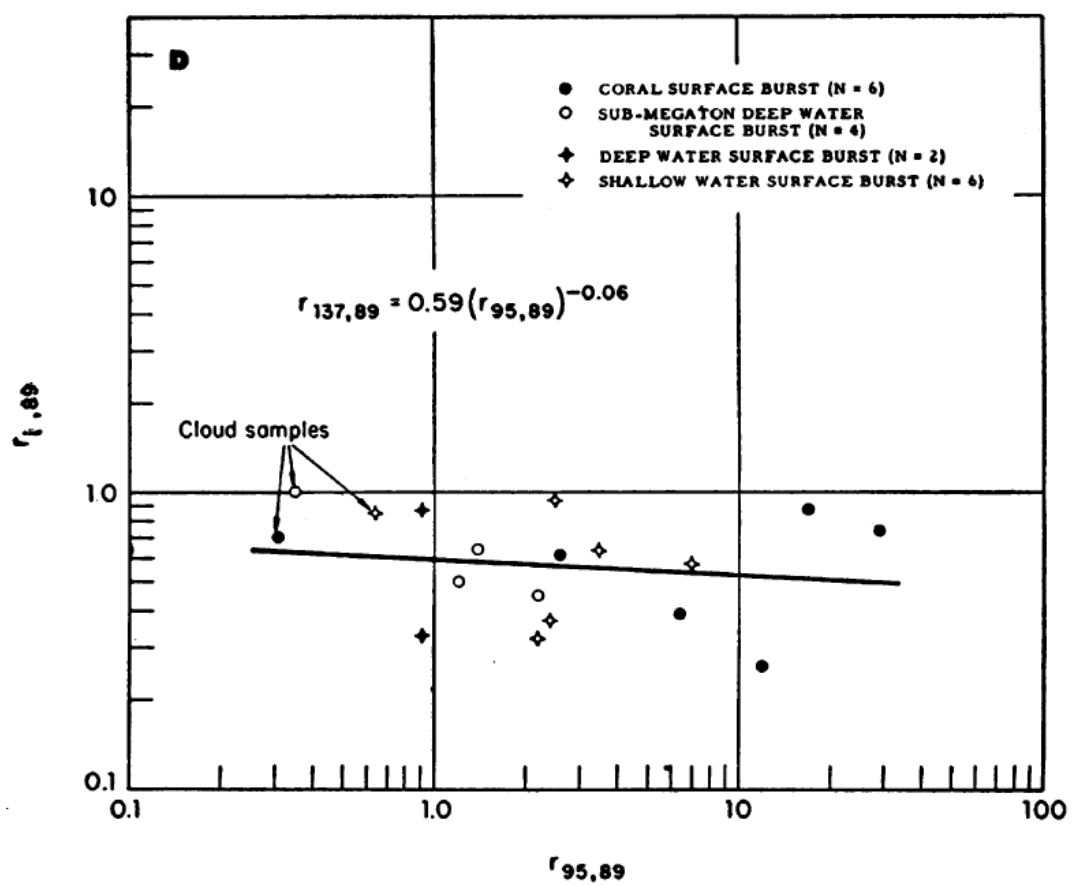




\section{Barium-140 and Te-132 are Somewhat Volatile}

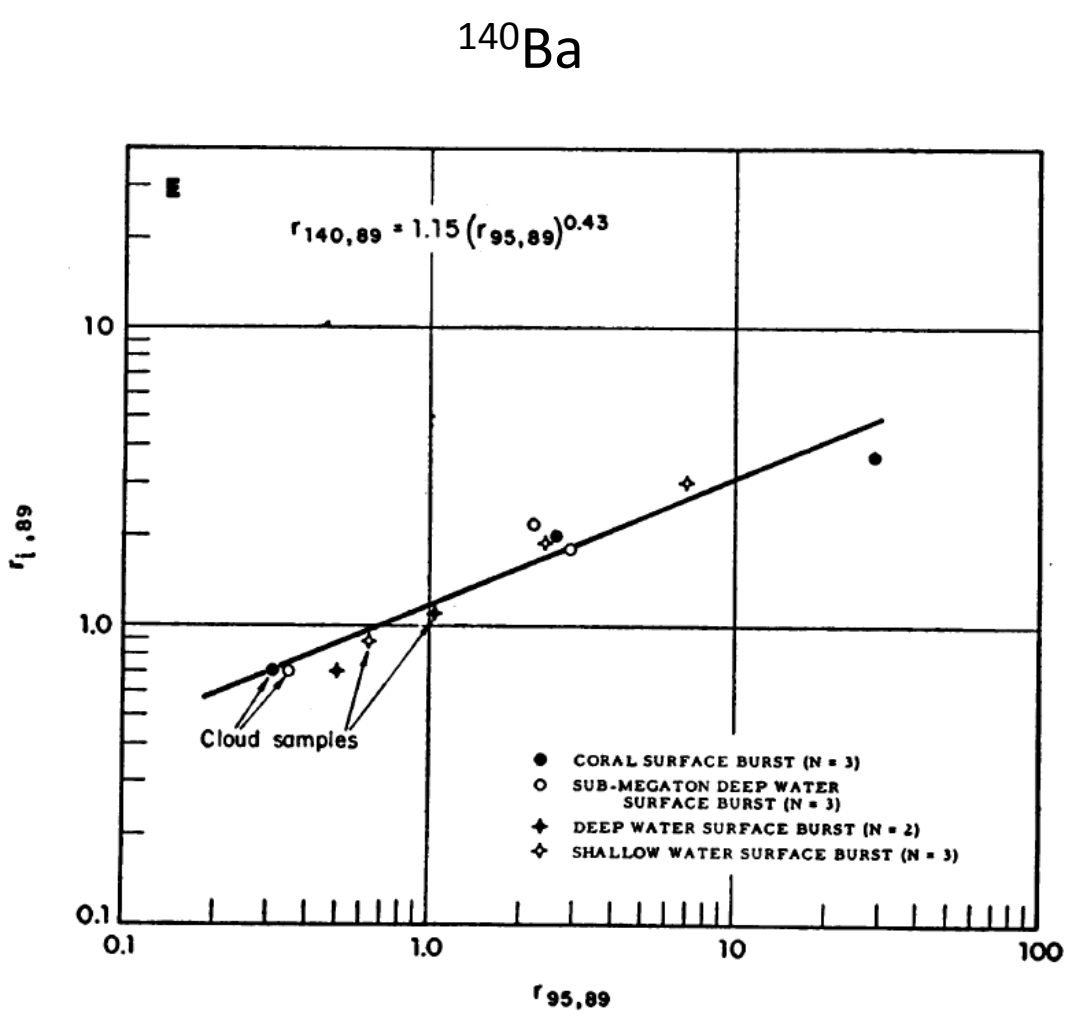

${ }^{132} \mathrm{Te}$

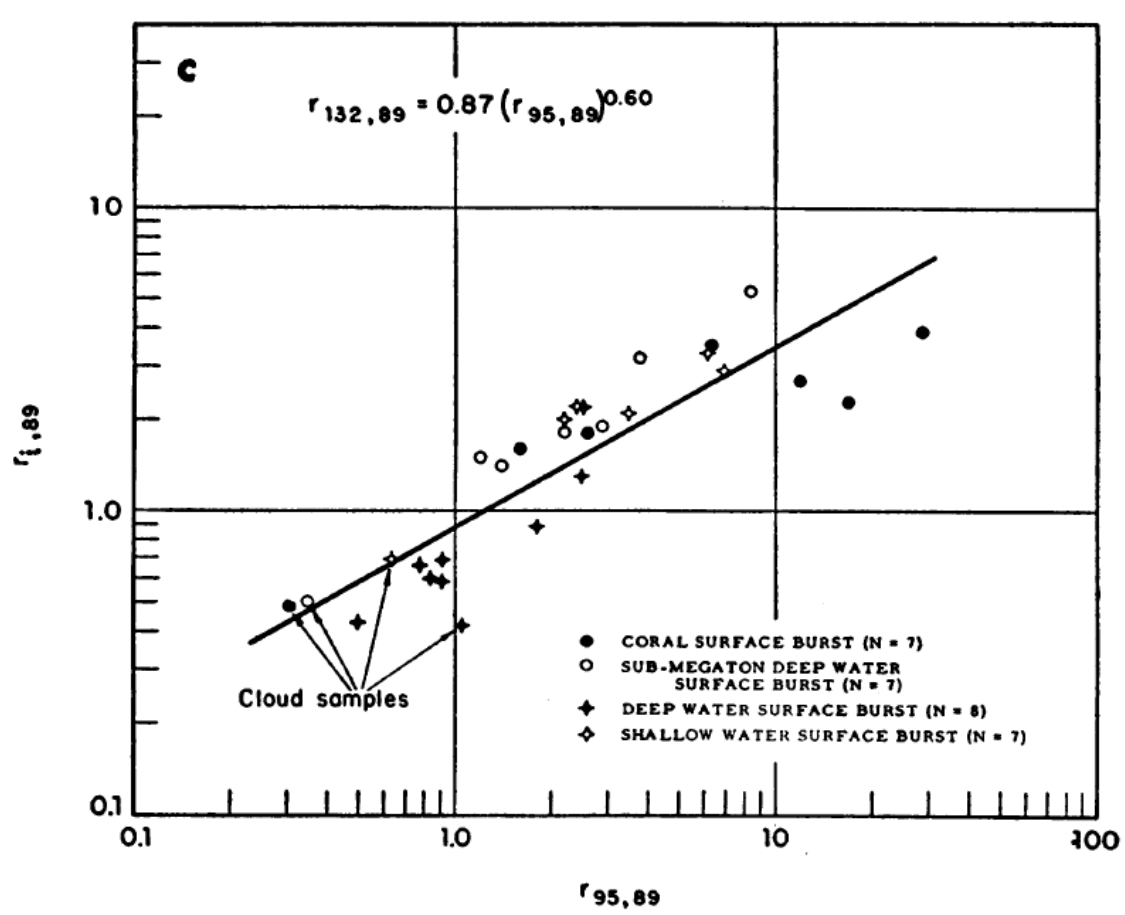




\section{$\mathrm{U}-237$ and Np-239 are Refractory}

${ }^{237} \mathrm{U}$

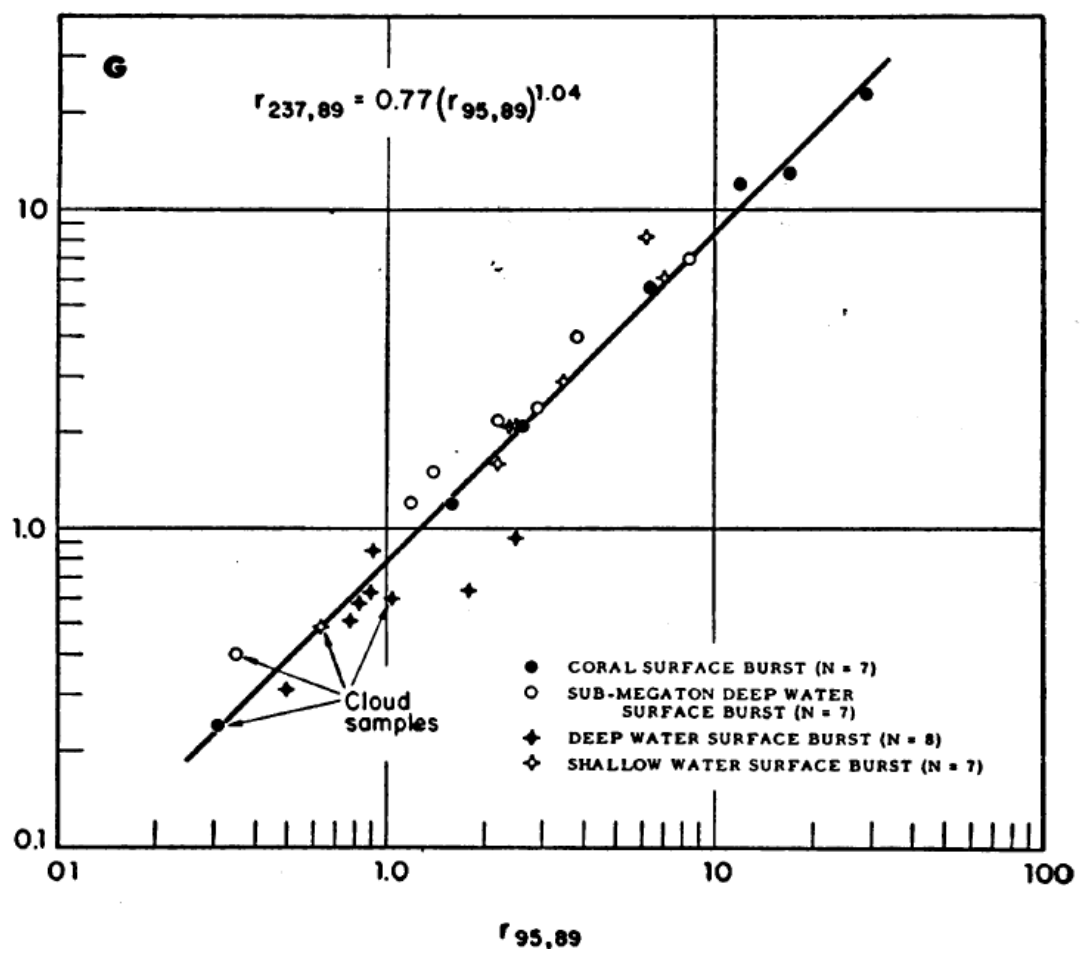

${ }^{239} \mathrm{~Np}$

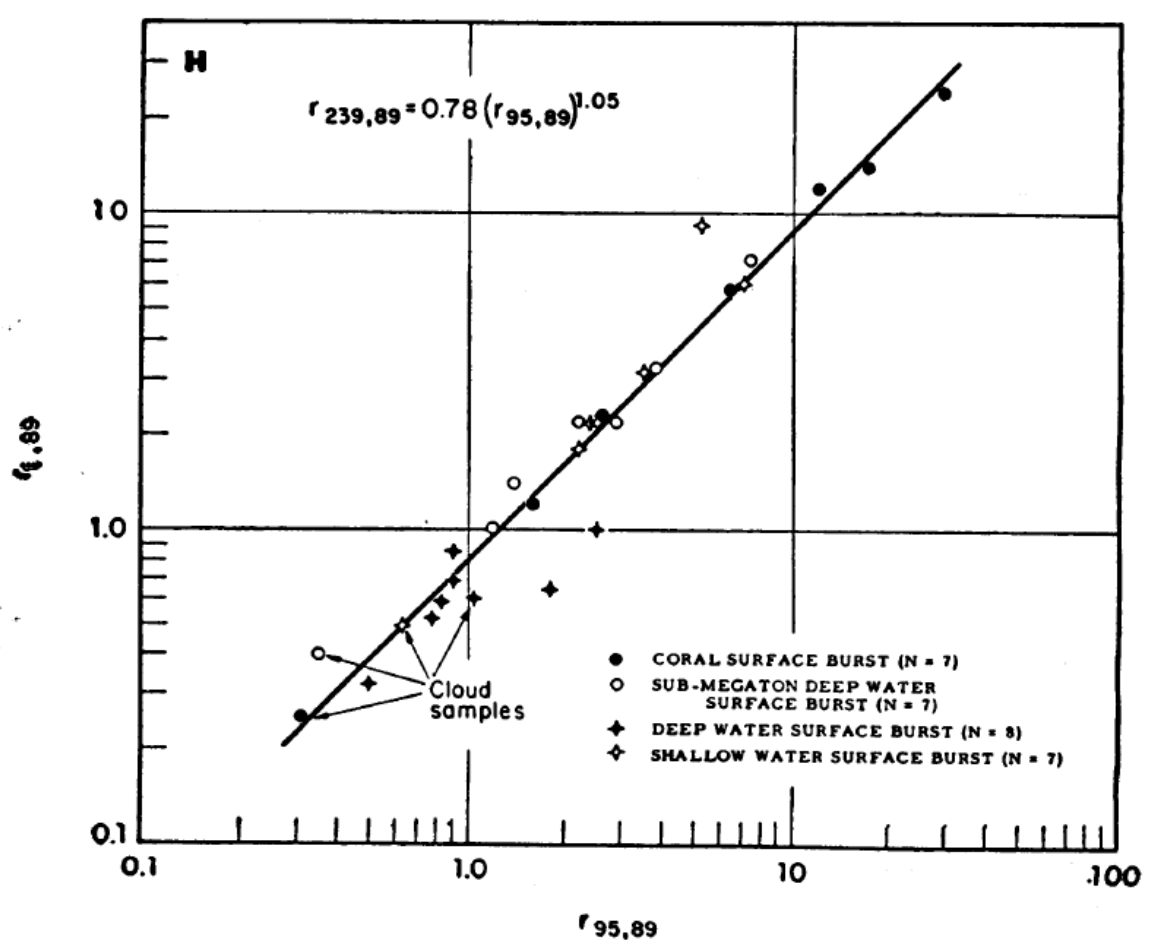




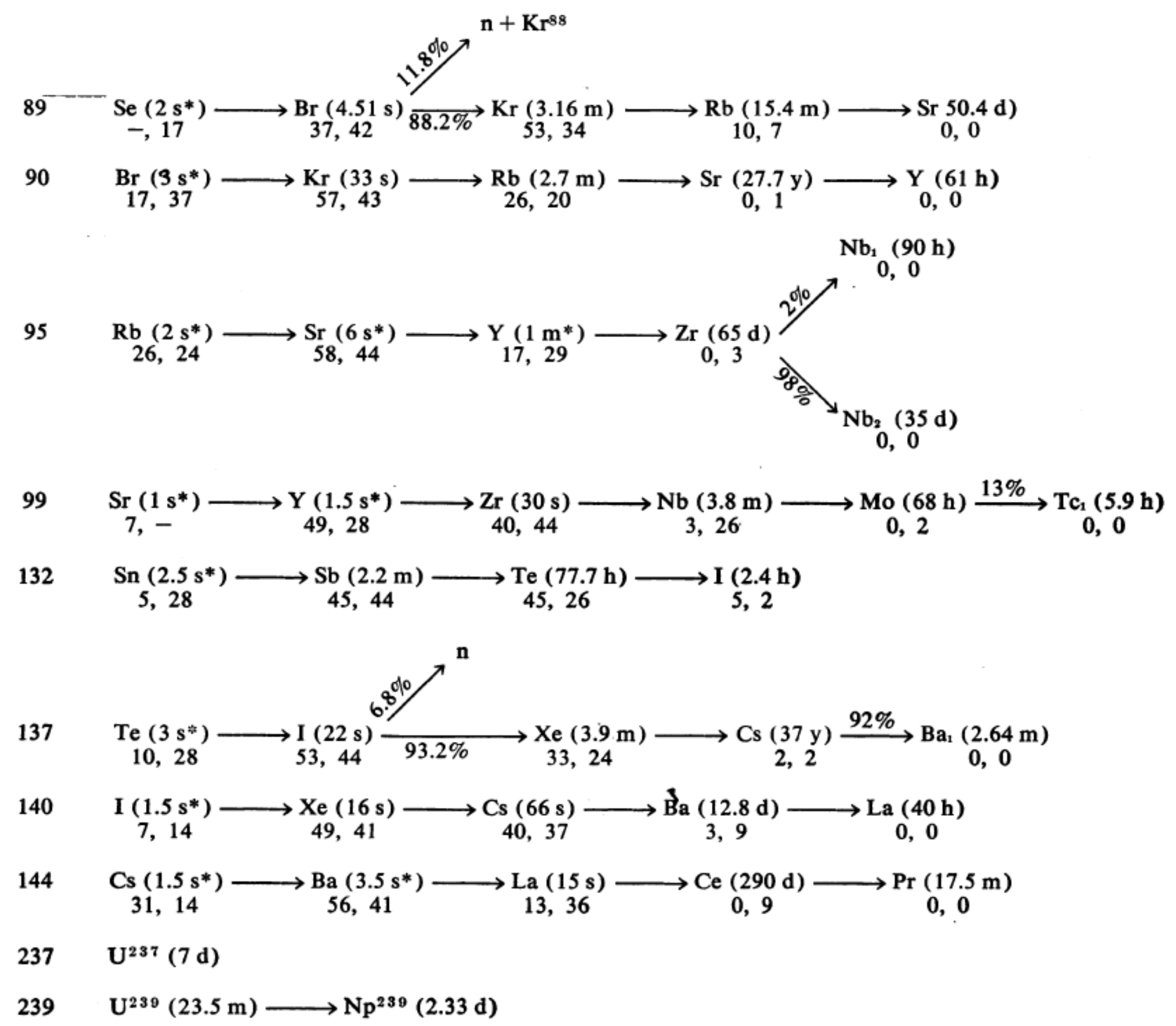




\section{Correlation of the log slope with}

Volatility

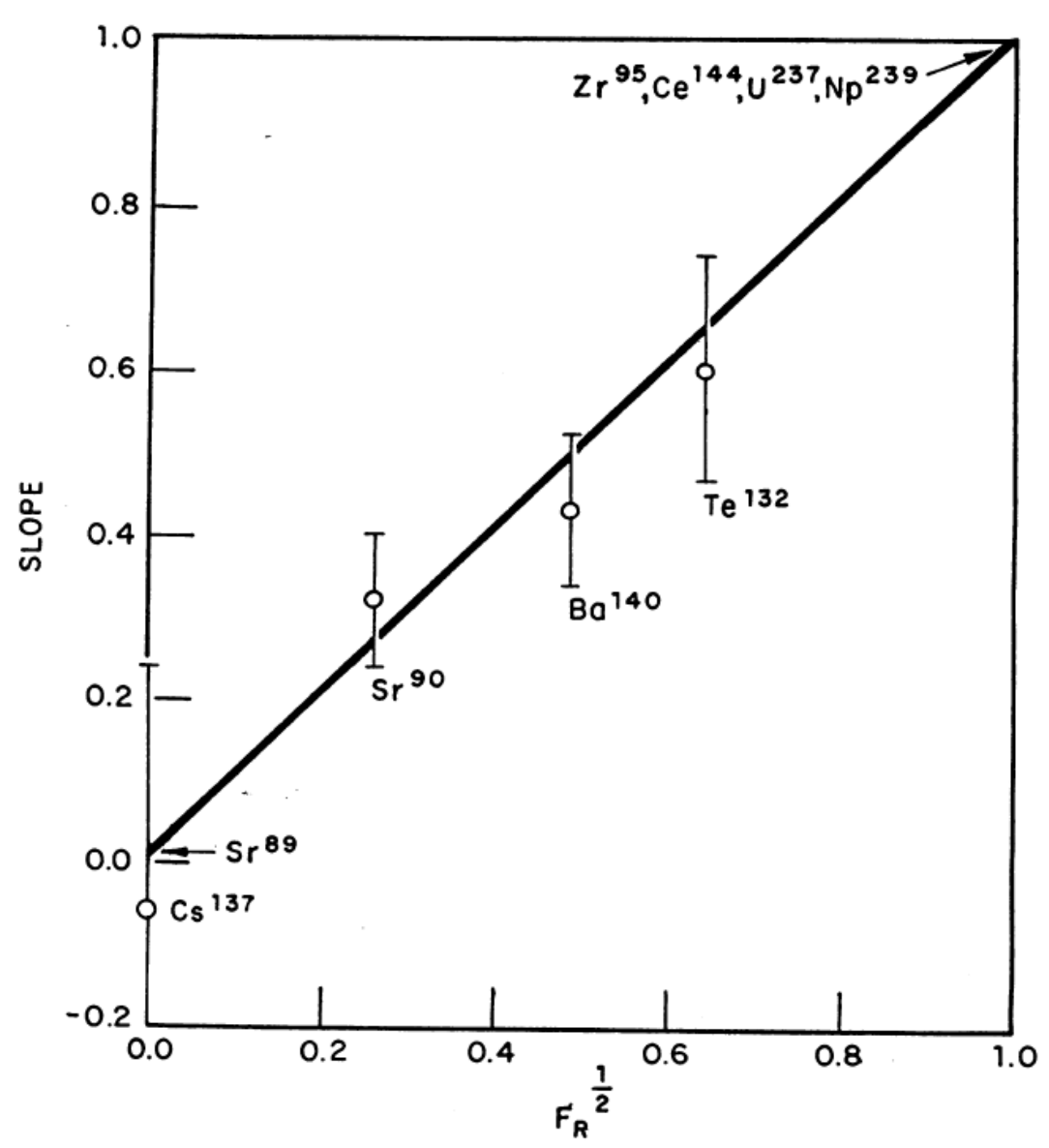

Fig. 3. Dependence of correlation slope on volatility of the precursor.
- The $F_{r} 1 / 2$ is the fraction of refractory precursors at 35 seconds.

- 35 seconds is approximately the time when particulates condense from the fireball. 


\section{How to Correct for Fractionation}

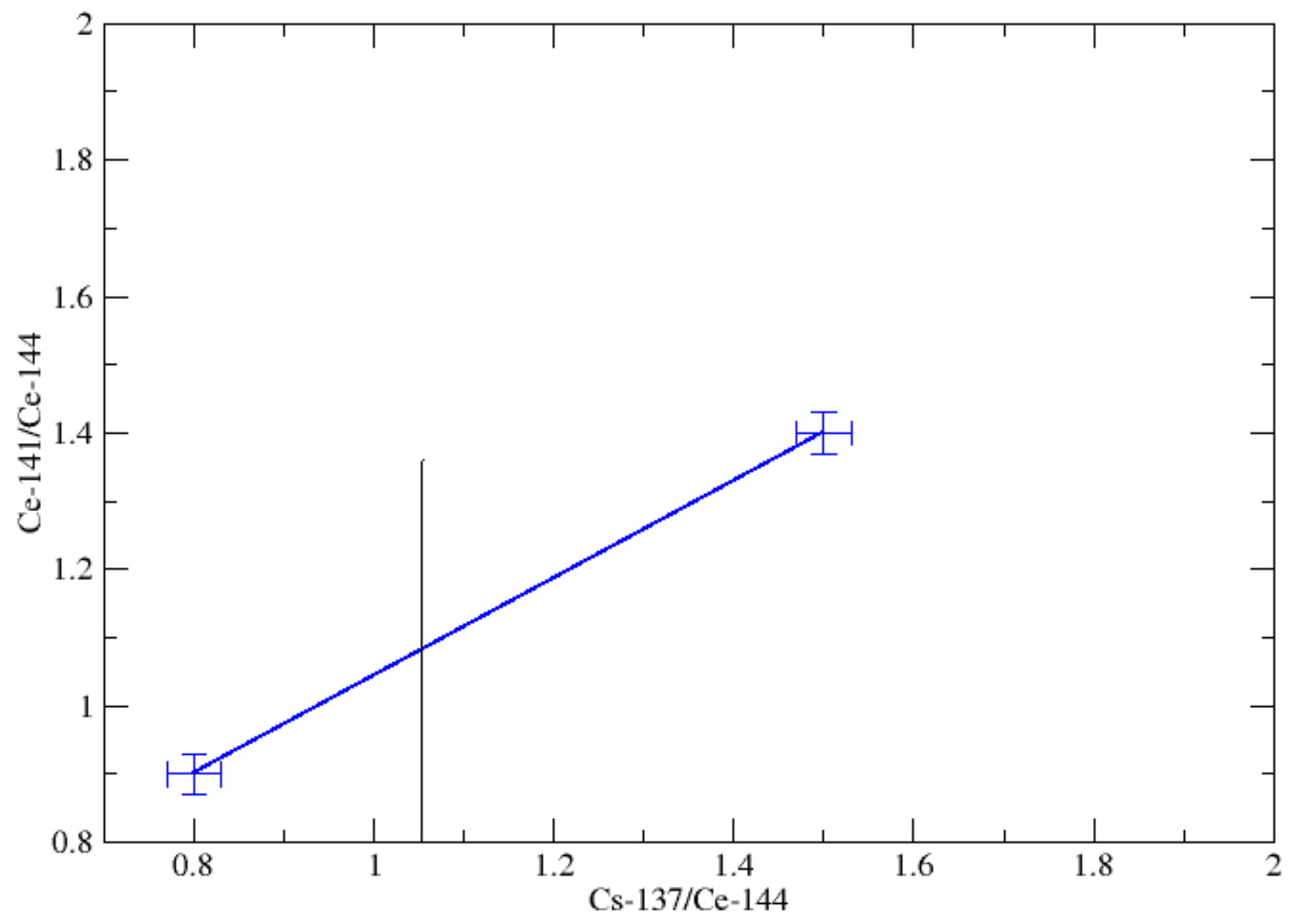




\section{Environmental Contamination}

- If activated dirt is incorporated into the debris sample then isotopes, such as, ${ }^{239} \mathrm{~Np}$ and natural uranium can contaminate the data.

- ${ }^{160} \mathrm{~Tb}$ or ${ }^{134} \mathrm{Cs}$ (in excess of the independent fission yield) may be used to remove this contamination.

- Isotope ratios that trend against these contaminant isotopes can be corrected by extrapolation to zero. 


\section{C.C. Wendel et al. / Environment International 59 (2013) 92-102}

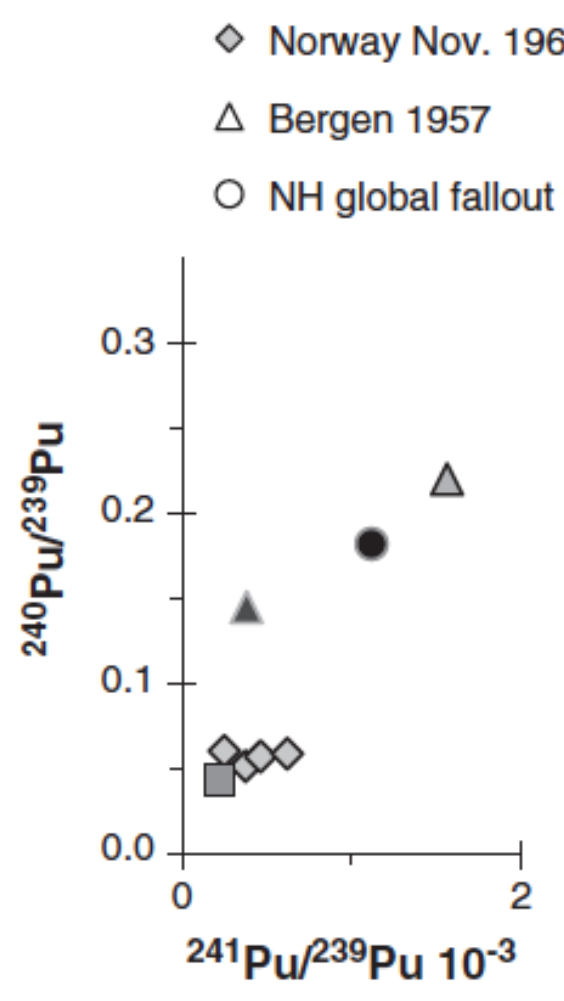

$\square$ Semipalatinsk *

A Røros 1962

- High yield weapon debris $\ddagger$

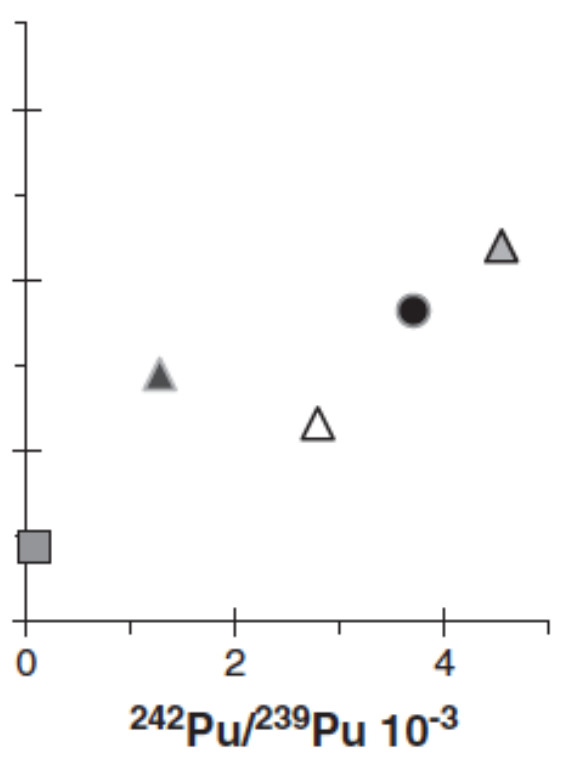

- NH global fallout **

$\triangle$ Røros 1963

Fig. 4. Atom ratios of $\mathrm{Pu}(241 \mathrm{Pu} / 239 \mathrm{Pu}, 242 \mathrm{Pu} / 239 \mathrm{Pu}$ and $244 \mathrm{Pu} / 239 \mathrm{Pu}$ ) (vertical axes) plotted against 240Pu/239Pu (horizontal axis). Reference date 01 January 2012. The November 1962 samples were individually analysed, while the autumn and spring samples from Bergen and Røros in 1957, 1962 and 1963 respectively were based on pooled samples from each period and site. Literature data from *Beasley et al. (1998) based on measurements of soils at ground zero in Semipalatinsk; **Kelley et al. (1999) soil samples collected worldwide; +Winkler (2007) sediment profile from Lake Erie; fLachner et al. (2010), mixed high yield weapon debris from the Bikini atoll. 